\title{
BCll polymorphism of the glucocorticoid receptor and adrenal crisis in primary adrenal insufficiency
}

\section{Kathrin Zopf', Kathrin R Frey², Tina Kienitz' ${ }^{1}$, Manfred Ventz'1, Britta Bauer ${ }^{3}$ and Marcus Quinkler ${ }^{3}$}

${ }^{1}$ Department of Endocrinology, Diabetes and Nutrition, Charité - Universitätsmedizin Berlin, Freie Universität Berlin, Humboldt-Universität zu Berlin, and Berlin Institute of Health, Berlin, Germany

${ }^{2}$ Department of Medicine I, Endocrine and Diabetes Unit, University Hospital, University of Würzburg, Würzburg, Germany

${ }^{3}$ Endocrinology in Charlottenburg, Berlin, Germany
Correspondence

should be addressed

to $\mathrm{M}$ Quinkler

Email

marcusquinkler@t-online.de

\begin{abstract}
Context: Patients with primary adrenal insufficiency (PAI) or congenital adrenal hyperplasia

genetically determined by polymorphisms of the glucocorticoid receptor (GR).

Objectives: To determine if a number of intercurrent illnesses and $A C$ are associated with the GR gene polymorphism $B c / l$ in patients with PAl and $\mathrm{CAH}$.

Design and patients: This prospective, longitudinal study over $37.7 \pm 10.1$ months included $47 \mathrm{PAI}$ and $25 \mathrm{CAH}$ patients. During the study period, intercurrent illness episodes and AC were documented.

Results: The study period covered 223 patient years in which $21 \mathrm{AC}$ occurred (9.4 AC/100 pat years). There were no significant differences between $B c / l$ polymorphisms (CC $(n=29)$, CG $(n=34)$ and GG $(n=9))$ regarding BMI, hydrocortisone equivalent daily dose and blood pressure. We did not find a difference in the number of intercurrent illnesses/ patient year among $B c / l$ polymorphisms (CC ( $1.5 \pm 1.4$ /pat year), CG (1.2 $\pm 1.2 /$ pat year) and GG (1.6 $\pm 2.2 /$ pat year)). The occurrence of AC was not significantly different among the homozygous (GG) genotype (32.5 AC/100 pat years), the CC genotype (6.7 AC/100 pat years) and the CG genotype (4.9 AC/100 pat years). Concomitant hypothyroidism was the highest in the GG genotype group (5/9), compared to others (CC (11/29) and CG (11/34)). Conclusions: Although sample sizes were relatively small and results should be interpreted with caution, this study suggests that the GR gene polymorphism Bc/l may not be associated with the frequencies of intercurrent illnesses and AC.
\end{abstract}

\section{Key Words}

- adrenal insufficiency
- adrenal crisis

- cortisol

- hydrocortisone

- polyglandular autoimmune syndrome

\section{Introduction}

Polymorphisms of the glucocorticoid receptor (GR) may influence the sensitivity to glucocorticoids by altering the GR expression (e.g. reducing transcription) and influencing transactivation and transrepression of target genes. The BclI single nucleotide polymorphism (SNP)
$(C>G)$ is known to increase glucocorticoid sensitivity (1, $2,3)$. This GR polymorphism works as part of a conserved haplotype and has repeatedly been associated with mood disorders and psychopathology (4), such as hypomania (5) and bulimia nervosa (6). The BclI polymorphism has

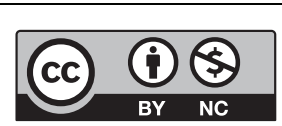

This work is licensed under a Creative Commons Attribution-NonCommercial 4.0 International License. 
also been associated with hypertension (7), metabolic syndrome (8), and especially hyperinsulinemia and obesity (9) indicating that the BclI SNP may alter GR functionality. In patients with bronchial asthma, the $B c l$ polymorphism seems to at least partially explain the development of a severe form of asthma associated with resistance to glucocorticoids (10).

Patients with adrenal insufficiency need a lifelong glucocorticoid replacement therapy $(11,12)$, which needs to be tailored individually to the daily needs, to stress situations, and intercurrent illnesses such as infectious diseases (13). This is even more important since the daily dose of hydrocortisone was lowered in recent years to an average of $20 \mathrm{mg}$ per day. Failure of dose adaptations in situations with a high need for glucocorticoids is likely to lead to adrenal crisis (AC), which is a major threat to patients with AI (14) and a major cause for the increased mortality (15). The pathogenesis and progression of AC are still not well understood, but glucocorticoid resistance due to increased tumor necrosis factor $\alpha$ (TNF- $\alpha)$ seems to play a major role $(16,17,18,19)$.

Recently, we could show that bone mineral density in patients with adrenal insufficiency is at least partially dependent on the BclI polymorphism of the GR (20). This triggers the question if intercurrent illnesses, their duration and the occurrence of AC might be influenced by the BclI polymorphism. Therefore, we included 72 patients with adrenal insufficiency (47 patients with primary adrenal insufficiency (PAI) and 25 patients with congenital adrenal hyperplasia $(\mathrm{CAH})$ ) in a prospective documentation of their intercurrent illness episodes and their AC frequency over a mean of 37.7 months. In all patients, the BclI polymorphism was determined and the groups with wild-type (CC), homozygous mutant (GG) and heterozygous mutant (CG) genotypes were compared regarding intercurrent illnesses and AC.

\section{Methods}

\section{Design and patients}

In a prospective study, patients from one endocrine university outpatient clinic were included. Inclusion criteria were PAI or CAH verified by reviewing medical records. Patients under the age of 18 years, patients diagnosed with bone metastasis, secondary adrenal insufficiency, adrenal insufficiency due to long-term pharmacological glucocorticoid treatment, adrenocortical carcinoma and patients with less than 12 months duration of disease were excluded. The study protocol was approved by the Charite University hospital ethics committee (EA1/027/10) and all patients gave written informed consent prior to participation. All clinical data, including the nature of hormone replacement therapies, were documented. The dose of glucocorticoid was converted into milligrams of hydrocortisone equivalent $(0.29 \mathrm{mg}$ dexamethasone $=3.33 \mathrm{mg}$ prednisolone $=20 \mathrm{mg}$ hydrocortisone) (21). The daily hydrocortisone equivalent intake was corrected for body surface area.

Forty-seven patients suffering from PAI (36 women, 11 men) and 25 patients with CAH (14 women, 11 men; salt-wasting $n=17$, simple-virilizing $n=8$ ) were included in the study. Most patients with PAI were treated with hydrocortisone $(n=35)$ or prednisolone $(n=11)$. Patients with CAH were treated with either hydrocortisone $(n=10)$, prednisolone $(n=5)$ or dexamethasone $(n=3)$ alone, or a combination of prednisolone and/or dexamethasone $(n=1), \quad$ a combination of hydrocortisone and dexamethasone $(n=4)$ or a combination of hydrocortisone and prednisolone $(n=2)$. Cohort characteristics are displayed in Table 1.

\section{Clinical follow-up}

During the study period, patients attended the endocrine outpatient clinic on a regular basis (on average, every six months). All patients were instructed on glucocorticoid dose adaptation: Doubling the replacement dose in the case of minor stress like flu-like symptoms, tripling or quadrupling the dose in the case of high fever or severe infections, intravenous hydrocortisone administration in the case of major stress like surgery, trauma or delivery. Patients were further instructed to immediately contact emergency care for parenteral hydrocortisone administration in the case of vomiting and diarrhea and received information on how to perform selftreatment in the case of unavailability of health care professionals (glucocorticoid self-injection, use of glucocorticoid suppositories). Patients were instructed to record information on days with intercurrent illnesses or an AC (parenteral glucocorticoid administration) in a patient's diary. This diary was checked throughout the study period, collected at the study end and the number of days with intercurrent illnesses and the events with parental glucocorticoid administration extracted. AC was defined if the following condition could be documented: Worsening of the general condition with signs and symptoms of glucocorticoid deficiency and at least two of 
Table 1 Clinical data of patients with primary adrenal insufficiency (PAI) and congenital adrenal hyperplasia (CAH) included in the study.

Male/female
Age (years)
BMI $\left(\mathrm{kg} / \mathrm{m}^{2}\right)$
Duration of disease (years)
Daily HC-equivalent dose $(\mathrm{mg})$
GC-dose per body surface $\left(\mathrm{mg} / \mathrm{m}^{2}\right)$
Fludrocortisone daily dose $(\mathrm{mg})$
DHEA daily dose $(\mathrm{mg})$
Concomitant disease
Hypothyroidism
Diabetes mellitus
Primary ovarian failure
Asthma

\begin{tabular}{c} 
All $(n=72)$ \\
\hline $22 / 50$ \\
$50.4 \pm 16.3$ \\
$26.4 \pm 5.9$ \\
$25.2 \pm 13.6$ \\
$26.5 \pm 9.7$ \\
$14.8 \pm 5.8$ \\
$0.11 \pm 0.08(n=61)$ \\
$20.8 \pm 6.6(n=15)$ \\
\\
$27 / 72$ \\
$13 / 72$ \\
$4 / 50$ \\
$5 / 72$
\end{tabular}

Primary adrenal insufficiency $(n=47)$ $11 / 36$

$56.3 \pm 15.3$

$25.6 \pm 4.6$

$19.9 \pm 11.8$

$25.8 \pm 8.6$

$14.4 \pm 5.9$

$0.10 \pm 0.07(n=44)$

$20.8 \pm 6.6(n=15)$

$\begin{array}{r}23 / 47 \\ 12 / 47 \\ 3 / 36 \\ 1 / 47 \\ \hline\end{array}$

Congenital adrenal hyperplasia $(n=25)$ $11 / 14$

$39.2 \pm 12 * * *$

$27.8 \pm 7.6$

$35 \pm 11.3^{* * *}$

$28.0 \pm 11.5$

$15.6 \pm 5.9$

$0.14 \pm 0.09(n=17)$

$-(n=0)$

Data are means \pm S.D.

$* * * P<0.001$ compared to PAI

$\mathrm{BMI}$, body mass index; DHEA, dehydroepiandrosterone; GC, glucocorticoid; HC, hydrocortisone.

the following findings demanding subsequent parenteral glucocorticoid administration: hypotension (systolic blood pressure $<100 \mathrm{mmHg}$ ), nausea or vomiting, severe fatigue, hyponatremia, hyperkalemia or hypoglycemia (17). Situations with parenteral glucocorticoid administration were evaluated retrospectively by the treating endocrinologists if they fulfilled the criteria of an AC crosschecking on the information from the patient (symptoms and complaints), from the protocol of the emergency services and from the reports of the hospital. Intercurrent illness was defined as any temporal illness where a transient increase in the glucocorticoid replacement dose was needed. The duration of the intercurrent illness was given by the number of days with complaints due to this event documented by the patient in the diary.

\section{Analysis of GR gene polymorphism Bcll}

The recently described PCR method detects not only homozygouswild-type(CC) and homozygousmutant(GG), but also heterozygous mutant (CG) genotypes: in addition to a 418-bp fragment present in all samples, homozygous wild-type individuals produce a 177-bp fragment, whereas homozygous mutant subjects have a 284-bp fragment (22). Total genomic DNA was isolated and PCR performed as reported previously (20). The following oligonucleotide primers were used: a reverse primer specific for the wildtype allele (5-CAATTCCTCTCTTAAAGAGATTG-3), a forward primer specific for the mutant allele (5-GACAAGTTATGTCTGCTGATG-3) and an outer forward
(5-AGAGCCCTATTCTTCAAACTG-3) and reverse primer (5-GAGAAATTCACCCCTACCAAC-3) (Eurofins MWG Operon, Ebersberg, Germany).

\section{Statistical analysis}

For a better clinical understanding, we calculated and displayed the frequency of $\mathrm{AC}$ as the number of $\mathrm{AC}$ per 100 patient years, whereas we calculated the frequency of intercurrent illnesses as the number of intercurrent illnesses per patient year.

Associations between genotypes and clinical features were evaluated using one-way ANOVA and KruskalWallis ANOVA depending on normality distribution. Post hoc pairwise comparison between groups was tested for significance using the Bonferroni test to correct for multiple comparisons. The statistical analysis of frequencies was performed by Chi-Square Test and Fisher's Exact test.

Analyses were performed using the statistical software package SPSS, version 15.0 (SPSS). Significance was accepted if $P<0.05$.

\section{Results}

The study period covered 223 patient years in which 21 AC occurred (9.4 AC/100 pat years) showing a trend of more frequent ACs in PAI than in CAH patients (9.99 vs 8.08 AC/100 pat years) (Table 2). However, the percentage of patients with an AC during the study period was not different

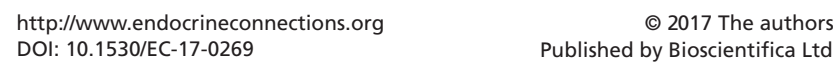




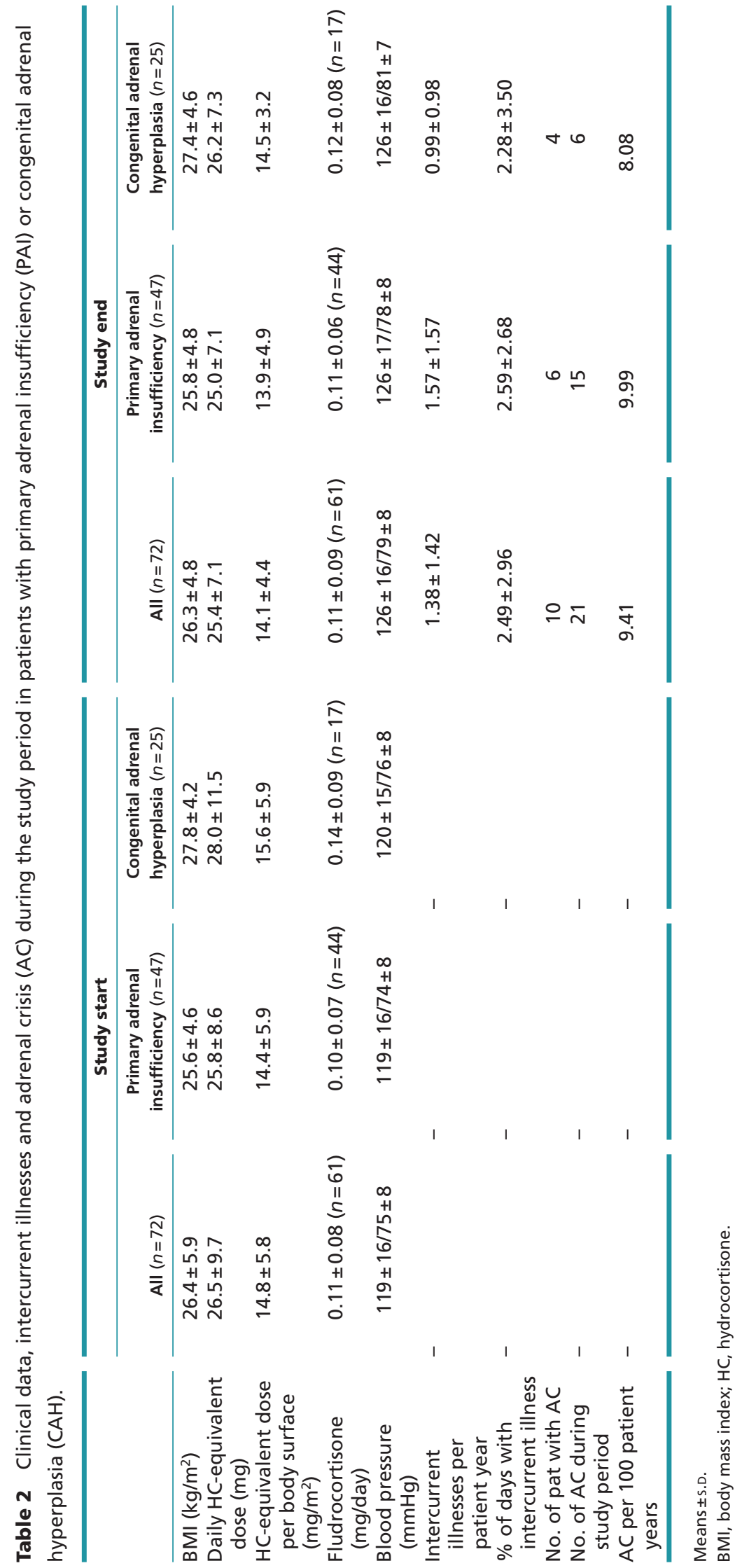


between PAI and CAH. 9 ACs were rated grade 1 and 12 ACs were rated grade 2 (grading according to Allolio (17)).

During the study period, BMI, daily HC-equivalent dose, fludrocortisone dose and blood pressure did not show any significant change (Table 2).

During the study period, a total of 310 episodes of intercurrent illness occurred. All episodes summarized up to a total of 1933 days with a mean duration of 6.2 days of an intercurrent illness episode. Patients experienced 1.38 intercurrent illnesses per patient year $(2.49 \%$ of all days were the days with intercurrent illnesses) with no significant differences between PAI and CAH patients (Table 2).

There were no significant differences among the three $B c l$ I polymorphisms (CC $(n=29)$, CG $(n=34)$ and GG $(n=9))$ regarding BMI, hydrocortisone equivalent daily dose and blood pressure (Table 3 ).

We did not find a difference in the number of intercurrent illnesses/patient year among the three $B c l$ I polymorphisms (CC (1.5 $\pm 1.4 /$ pat year), CG (1.2 $\pm 1.2 /$ pat year) and GG (1.6 $\pm 2.2 /$ pat year)). The occurrence of AC was not significantly different among the homozygous (GG) genotype (32.5 AC/100 pat years), the CC genotype (6.7 AC/100 pat years) and the CG genotype (4.9 AC/100 pat years) (Table 3). However, this tendency to higher frequency of $\mathrm{AC}$ in the homozygous (GG) genotype group was mainly due to one patient who had 8 ACs in the study period.
Concomitant hypothyroidism was the highest in the GG genotype group (5/9), compared to other groups (CC $(11 / 29)$ and CG (11/34)), whereas diabetes mellitus was most common in the CG genotype group.

\section{Discussion}

ACs occur in a substantial proportion of patients with adrenal insufficiency with an overall frequency of 5-17 AC/100 patient years in retrospective studies $(23,24,25$, $26,27)$, and $8.3 \mathrm{AC} / 100$ patient years in a prospective study (14). Our current study shows a frequency of 10 $\mathrm{AC} / 100$ patient years in PAI and $8.1 \mathrm{AC} / 100$ patient years in adult $\mathrm{CAH}$ patients. The latter is quite higher than the recently reported data (4.8-5.8 AC/100 pat years) from a retrospective $\mathrm{CAH}$ cohort (28). This might be due to the relatively high proportion of salt-wasting CAH patients in our cohort. Interestingly, all ACs occurred in the group of $\mathrm{CAH}$ patients with the salt-wasting form, leading to a frequency of $11.5 \mathrm{AC} / 110$ patient years in this group.

Precipitating causes of AC are mainly gastrointestinal infection, fever and other infections. Patients with additional comorbidities, such as diabetes mellitus, asthma, premature ovarian failure or hypothyroidism, are at a higher risk $(14,23,24)$.

The pathogenesis and progression of AC are still not well understood. It is suspected that TNF- $\alpha$ plays a major

Table 3 Clinical data at study start and intercurrent illness during the study period depending on the glucocorticoid receptor $B C / l$ single nucleotide polymorphism (SNP) in patients with primary adrenal insufficiency (PAI) and congenital adrenal hyperplasia (CAH).

\begin{tabular}{|c|c|c|c|}
\hline Bcll allelic variants & CC & CG & GG \\
\hline$N$ (female/male) & $29(20 / 9)$ & $34(23 / 11)$ & $9(7 / 2)$ \\
\hline $\mathrm{PAI} / \mathrm{CAH}$ & $19 / 10$ & $22 / 12$ & $6 / 3$ \\
\hline Age (years) & $48.3 \pm 15.8$ & $50.3 \pm 14.2$ & $57.6 \pm 24.2$ \\
\hline $\mathrm{BMI}\left(\mathrm{kg} / \mathrm{m}^{2}\right)$ & $26.8 \pm 7.2$ & $25.7 \pm 4.2$ & $27.4 \pm 6.7$ \\
\hline Duration of disease (years) & $25.4 \pm 14.5$ & $26.6 \pm 12.9$ & $19.1 \pm 12.8$ \\
\hline Daily HC-equivalent dose (mg) & $26.1 \pm 8.9$ & $27.2 \pm 11.3$ & $25.5 \pm 4.9$ \\
\hline HC-equivalent dose per body surface $\left(\mathrm{mg} / \mathrm{m}^{2}\right)$ & $14.4 \pm 4.7$ & $15.4 \pm 7.2$ & $14.1 \pm 2.9$ \\
\hline Blood pressure $(\mathrm{mmHg})$ & $117 \pm 13 / 73 \pm 8$ & $120 \pm 16 / 76 \pm 8$ & $124 \pm 22 / 76 \pm 7$ \\
\hline Fludrocortisone (mg/day) & $0.08 \pm 0.05$ & $0.11 \pm 0.10$ & $0.07 \pm 0.02$ \\
\hline \multicolumn{4}{|l|}{ Concomitant disease $(n)$} \\
\hline Hypothyroidism & 11 & 11 & 5 \\
\hline Diabetes mellitus & 4 & 8 & 1 \\
\hline Primary ovarian failure & 4 of 20 & 0 & 0 \\
\hline Asthma & 0 & 4 & 1 \\
\hline Intercurrent illnesses per patient year & $1.50 \pm 1.43$ & $1.22 \pm 1.15$ & $1.58 \pm 2.24$ \\
\hline$\%$ of days with intercurrent illness & $2.0 \pm 1.8$ & $2.7 \pm 3.3$ & $3.2 \pm 4.4$ \\
\hline No. of pat with $A C$ & 4 & 3 & 3 \\
\hline No. of AC during study period & 6 & 5 & 10 \\
\hline AC per 100 patient years & 6.67 & 4.89 & 32.47 \\
\hline
\end{tabular}

The GG genotype is known to have increased glucocorticoid sensitivity compared to the CG and CC genotypes. Means \pm S.D. AC, adrenal crisis; BMI, body mass index; HC, hydrocortisone. 
role. TNF- $\alpha$ levels increased considerably after endotoxin administration in adrenalectomized mice (19) and induced glucocorticoid insensitivity (29). A mice model with adrenal insufficiency showed an aberrant inflammatory response in sepsis (16). It is suspected that glucocorticoid resistance due to increased TNF- $\alpha$ might also play a major role in the pathophysiology of AC in humans (17).

As GR resistance plays a role in AC, we wanted to investigate the hypothesis if AI patients who carry a polymorphism of the GR leading to a more insensitive GR receptor are more prone to end up in an AC.

In our cohort, the more sensitive GG nucleotide of the $B c l$ I polymorphism was associated with a tendency to lower daily HC-equivalent doses and to higher BMI. In addition, there was also a tendency to more days with intercurrent illnesses in this group compared to the CC and CG nucleotides. However, this tendency might be explained by the higher frequency of hypothyroidism in this group. The latter is considered to be a risk factor for AC (23). We could not identify a significant difference between the nucleotide types of the $B c l$ I polymorphism regarding AC.

These are the first data regarding the number of intercurrent illnesses and the percentage of days with intercurrent illnesses with regard to the $B c l$ I polymorphism of the GR. It is interesting to note that a patient with AI had on average 9 days with intercurrent illnesses per year. This is comparable to the average number of sick days of German employees (10.8 days in 2016) (30). In addition, the average duration of an intercurrent illness was 6.5 days in patients with AI.

There are several limitations in this study. First, we used a relatively small patient cohort for a genetic association study and therefore the results need further replication. However, the strength of our study is the long study period with an average of 37.7 months. Second, it is still unknown how the BclI polymorphism exerts its effects. After administration of dexamethasone, serum cortisol levels were lower in G-allele carriers of the BclI polymorphism, pointing to a greater glucocorticoid sensitivity (1). However, the exact pathways remain to be elucidated.

In conclusion, we could neither detect a significant difference in the frequency and duration of intercurrent illness episodes nor in the frequency of AC regarding the BclI polymorphism of the GR.

\section{Declaration of interest}

The authors declare that there is no conflict of interest that could be perceived as prejudicing the impartiality of the research reported.

\section{Funding}

This work did not receive any specific grant from any funding agency in the public, commercial or not-for-profit sector.

\section{References}

1 van Rossum EF, Koper JW, van den Beld AW, Uitterlinden AG, Arp P, Ester W, Janssen JA, Brinkmann AO, de Jong FH, Grobbee DE, et al. Identification of the BclI polymorphism in the glucocorticoid receptor gene: association with sensitivity to glucocorticoids in vivo and body mass index. Clinical Endocrinology 200359 585-592. (doi:10.1046/j.1365-2265.2003.01888.x)

2 van Rossum EF \& Lamberts SW. Polymorphisms in the glucocorticoid receptor gene and their associations with metabolic parameters and body composition. Recent Progress in Hormone Research 200459 333-357. (doi:10.1210/rp.59.1.333)

3 Stevens A, Ray DW, Zeggini E, John S, Richards HL, Griffiths CE \& Donn R. Glucocorticoid sensitivity is determined by a specific glucocorticoid receptor haplotype. Journal of Clinical Endocrinology and Metabolism 200489 892-897. (doi:10.1210/jc.2003-031235)

4 Spijker AT \& van Rossum EF. Glucocorticoid receptor polymorphisms in major depression. Focus on glucocorticoid sensitivity and neurocognitive functioning. Annals of the New York Academy of Sciences 20091179 199-215. (doi:10.1111/j.17496632.2009.04985.x)

5 Spijker AT, Giltay EJ, van Rossum EF, Manenschijn L, Derijk RH, Haffmans J, Zitman FG \& Hoencamp E. Glucocorticoid and mineralocorticoid receptor polymorphisms and clinical characteristics in bipolar disorder patients. Psychoneuroendocrinology 201136 1460-1469. (doi:10.1016/j.psyneuen.2011.03.020) 6 Steiger H, Bruce K, Gauvin L, Groleau P, Joober R, Israel M, Richardson J \& Kin FN. Contributions of the glucocorticoid receptor polymorphism (Bcl1) and childhood abuse to risk of bulimia nervosa. Psychiatry Research 2011187 193-197. (doi:10.1016/j. psychres.2010.10.021)

7 van MD, van Greevenbroek MM, Schaper NC, Henry RM, Geelen CC, van Rossum EF, Nijpels G, 't Hart LM, Schalkwijk CG, van der Kallen CJ, et al. BclI glucocorticoid receptor polymorphism in relation to cardiovascular variables: the Hoorn and CODAM studies. European Journal of Endocrinology 2015173 455-464. (doi:10.1530/ EJE-15-0381)

8 Wester VL, Koper JW, van den Akker EL, Franco OH, Stolk RP \& van Rossum EF. Glucocorticoid receptor haplotype and metabolic syndrome: the Lifelines cohort study. European Journal of Endocrinology 2016175 645-651. (doi:10.1530/EJE-16-0534)

9 Manenschijn L, van den Akker EL, Lamberts SW \& van Rossum EF. Clinical features associated with glucocorticoid receptor polymorphisms. An overview. Annals of the New York Academy of Sciences 20091179 179-198. (doi:10.1111/j.1749-6632.2009.05013.x)

10 Pietras T, Panek M, Tworek D, Oszajca K, Wujcik R, Gorski P, Kuna P $\&$ Szemraj J. The Bcl I single nucleotide polymorphism of the human glucocorticoid receptor gene h-GR/NR3C1 promoter in patients with bronchial asthma: pilot study. Molecular Biology Reports $20113 \mathbf{8}$ 3953-3958. (doi:10.1007/s11033-010-0512-5)

11 Arlt W \& Allolio B. Adrenal insufficiency. Lancet $2003 \mathbf{3 6 1}$ 1881-1893. (doi:10.1016/S0140-6736(03)13492-7)

12 Koetz K, Kienitz T \& Quinkler M. Management of steroid replacement in adrenal insufficiency. Minerva Endocrinologica 201035 61-72.

13 Johannsson G, Falorni A, Skrtic S, Lennernas H, Quinkler M, Monson JP \& Stewart PM. Adrenal insufficiency: review of clinical outcomes with current glucocorticoid replacement therapy. Clinical Endocrinology 201582 2-11. (doi:10.1111/cen.12603)

14 Hahner S, Spinnler C, Fassnacht M, Burger-Stritt S, Lang K, Milovanovic D, Beuschlein F, Willenberg HS, Quinkler M \& 
Allolio B. High incidence of adrenal crisis in educated patients with chronic adrenal insufficiency: a prospective study. Journal of Clinical Endocrinology and Metabolism 2015100 407-416. (doi:10.1210/ jc.2014-3191)

15 Erichsen MM, Lovas K, Fougner KJ, Svartberg J, Hauge ER, Bollerslev J, Berg JP, Mella B \& Husebye ES. Normal overall mortality rate in Addison's disease, but young patients are at risk of premature death. European Journal of Endocrinology 2009160 233-237. (doi:10.1530/EJE-08-0550)

16 Ai J, Guo L, Zheng Z, Wang SX, Huang B \& Li XA. Corticosteroid therapy benefits septic mice with adrenal insufficiency but harms septic mice without adrenal insufficiency. Critical Care Medicine 2015 43 e490-e498. (doi:10.1097/CCM.0000000000001264)

17 Allolio B. Extensive expertise in endocrinology. Adrenal crisis. European Journal of Endocrinology 2015172 R115-R124. (doi:10.1530/ EJE-14-0824)

18 Caratti G, Matthews L, Poolman T, Kershaw S, Baxter M \& Ray D. Glucocorticoid receptor function in health and disease. Clinical Endocrinology 201583 441-448. (doi:10.1111/cen.12728)

19 Koniaris LG, Wand G \& Wright TM. TNF mediates a murine model of Addison's crisis. Shock 200115 29-34. (doi:10.1097/00024382200115010-00005)

20 Koetz KR, van Rossum EF, Ventz M, Diederich S \& Quinkler M. BclI polymorphism of the glucocorticoid receptor gene is associated with increased bone resorption in patients on glucocorticoid replacement therapy. Clinical Endocrinology 201378 831-837. (doi:10.1111/ cen.12096)

21 Rivkees SA \& Crawford JD. Dexamethasone treatment of virilizing congenital adrenal hyperplasia: the ability to achieve normal growth. Pediatrics 2000106 767-773. (doi:10.1542/peds.106.4.767)

22 Gergics P, Patocs A, Majnik J, Balogh K, Szappanos A, Toth M \& Racz K. Detection of the Bcl I polymorphism of the glucocorticoid receptor gene by single-tube allele-specific polymerase chain reaction. Journal of Steroid Biochemistry and Molecular Biology 2006100 161-166. (doi:10.1016/j.jsbmb.2006.04.004)
23 White K \& Arlt W. Adrenal crisis in treated Addison's disease: a predictable but under-managed event. European Journal of Endocrinology 2010162 115-120. (doi:10.1530/EJE-09-0559)

24 Hahner S, Loeffler M, Bleicken B, Drechsler C, Milovanovic D, Fassnacht M, Ventz M, Quinkler M \& Allolio B. Epidemiology of adrenal crisis in chronic adrenal insufficiency - the need for new prevention strategies. European Journal of Endocrinology 2010162 597-602. (doi:10.1530/EJE-09-0884)

25 Meyer G, Neumann K, Badenhoop K \& Linder R. Increasing prevalence of Addison's disease in German females: health insurance data 2008-2012. European Journal of Endocrinology 2014170 367-373. (doi:10.1530/EJE-13-0756)

26 Ritzel K, Beuschlein F, Mickisch A, Osswald A, Schneider HJ, Schopohl J \& Reincke M. Clinical review: outcome of bilateral adrenalectomy in Cushing's syndrome: a systematic review. Journal of Clinical Endocrinology and Metabolism 201398 3939-3948. (doi:10.1210/jc.2013-1470)

27 Smans LC, Van der Valk ES, Hermus AR \& Zelissen PM. Incidence of adrenal crisis in patients with adrenal insufficiency. Clinical Endocrinology 201684 17-22. (doi:10.1111/cen.12865)

28 Reisch N, Willige M, Kohn D, Schwarz HP, Allolio B, Reincke M, Quinkler M, Hahner S \& Beuschlein F. Frequency and causes of adrenal crises over lifetime in patients with 21-hydroxylase deficiency. European Journal of Endocrinology 2012167 35-42. (doi:10.1530/EJE-12-0161)

29 Van BT, Vandevyver S, Dejager L, Van HF, Pinheiro I, Petta I, Engblom D, Kleyman A, Schütz G, Tuckermann J, et al. Tumor necrosis factor inhibits glucocorticoid receptor function in mice: a strong signal toward lethal shock. Journal of Biological Chemistry 2011 286 26555-26567. (doi:10.1074/jbc.M110.212365)

30 Institut für Arbeitsmarkt- und Berufsforschung. Krankheitsbedingte Fehltage im Jahr je Arbeitnehmer in Deutschland von 1991 bis 2016. Hamburg, Germany: Statista GmbH, 2017. (available at: https://de.statista.com/statistik/daten/studie/13441/umfrage/ entwicklung-der-jaehrlichen-anzahl-krankheitsbedingter-fehltage-jearbeitnehmer/)

Received in final form 24 September 2017

Accepted 26 September 2017

Accepted Preprint published online 27 September 2017 http://www.endocrineconnections.org DOI: 10.1530/EC-17-0269 (c) 2017 The authors Published by Bioscientifica Ltd

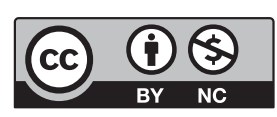

This work is licensed under a Creative Common Attribution-NonCommercial 4.0 International License. 